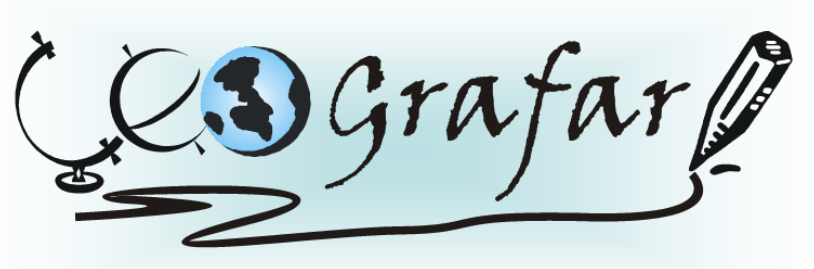

Revista Eletrônica do Programa de Pós-Graduação em Geografia - UFPR

\title{
ANÁLISE TEMPORAL SOBRE AS “TERRAS CAÍDAS” NO MÉDIO SOLIMÕES/COARI (AM)
}

\author{
FRANCIMARA TORRES DE FREITAS ${ }^{1}$ \\ ADOREA REBELLO ALBUQUERQUE ${ }^{2}$
}

\begin{abstract}
RESUMO
Na Amazônia, o termo Terras Caídas é atribuído ao processo de solapamento das margens de grandes rios, que na pós-fase de ocorrência provoca mudanças na morfologia dos padrões de drenagem dos canais. Com referência ao tema, este trabalho tem a finalidade de identificar mudanças no médio curso do rio Solimões no trecho entre Coari e o Terminal Aquaviário da Petrobras - a partir da análise temporal-comparativa sobre quatro áreas selecionadas de modo distinto, entre as margens direita e esquerda, no período 1987 a 2008, utilizando imagens de satélite. Resultados demonstraram que na Área 1 (margem esquerda) as alterações na configuração e morfologia das margens, representaram $72 \%$ do total de dados interpretados, evidenciando-a como a área onde as mudanças foram maiores. Em contrapartida, mudanças mínimas em total de $4 \%$ foram indicadas na Área 2 (margem direita). As análises granulométricas realizadas com dez amostras de solo, obtidas nas quatro áreas, indicaram para nove perfis, texturas do tipo franco-siltosa. Somente a Área 4 (margem esquerda) apresentou textura franco-arenosa. Estas condições evidenciam altos níveis de instabilidade para o material sedimentar das várzeas amazônicas, estabelecidas por valores elevados da fração silte expressos entre $347,5 \mathrm{~g} / \mathrm{kg}$ e $739 \mathrm{~g} / \mathrm{kg}$. O que se pode concluir, é que, em função da fragilidade do material depositado, a ação erosiva da água produz grandes reentrâncias na morfologia das margens, em que a erosão fluvial constitui o resultado de uma correlação de fatores controladores, onde se destacam hidrodinâmica de canais e tipos de sedimentos erodidos e depositados.
\end{abstract}

Palavras-chaves: Amazônia, Terra caída, Erosão fluvial, Solimões, Coari

\footnotetext{
${ }^{1}$ MSc. /UFAM ; e-mail: francimaracoari@yahoo.com.br

${ }^{2}$ Dra. UFAM/UFRJ; e-mail: adorea27@yahoo.com
} 


\title{
TEMPORAL ANALYSIS ABOUT “FALLEN LAND”IN THE MIDDLE SOLIMÕES/COARI (AM)
}

\begin{abstract}
In the Amazon, the expression fallen lands is used to indicate the process of overlapping of the edges of big rivers. This process causes changes in the morphology of the draining patterns of the channels in the post phase of occurrence. Regarding the theme, this work aims at identifying changes in the mean course of the Solimões River - in the stretch of Coari and the water way station of Petrobras. based on the comparative temporal analysis done with four areas selected in different ways, among the right and left edges, within the period of 1987 and 2008, using satellite images. The results showed that in Area 1 (left edge) the alterations in configuration and morphology of the edges represented $72 \%$ of the total from the interpreted data, pointing this area as the one where the changes were bigger. On the other hand, minimum changes in a total of $4 \%$ were indicated in Area 2 (right edge). The grain size analysis carried out with ten samples of the soil, taken from the four areas, indicated silt loam texture for nine of the profiles. Only Area 4 (left edge) presented sandy loam texture. These conditions show high levels of instability for sedimentary material from the Amazonian wet lands which were established by high values of silt fraction expressed between $347,5 \mathrm{~g} / \mathrm{kg}$ and $739 \mathrm{~g} / \mathrm{kg}$. What one can conclude from that is that due to the frailty of the material deposited, the erosive action of water produces big overlapping in the morphology of the edges, where the fluvial erosion constitutes the result of a correlation of controlling factors, from which channels' hydrofoil and the types of the eroded and deposited sediments are emphasized.
\end{abstract}

Key words: Amazon, fallen lands, fluvial erosion, Solimões, Coari

\section{INTRODUÇÃO}

Na complexa rede hidrográfica da Amazônia ocorrem fenômenos curiosos relacionados aos processos de erosão fluvial. Um deles muito conhecido, diz respeito aos movimentos de terras nas margens dos canais conhecidos por "Terras Caídas", processo comum em rios de água branca, como o Solimões.

Com referência a este fenômeno amazônico, o presente trabalho teve a finalidade de apresentar a dinâmica desse processo erosivo, correlacionada aos fatores de natureza hidrográfica e geomorfológica, a partir de uma análise geográfica no médio curso do rio Solimões, visando contribuir para a melhor compreensão deste fenômeno. A necessidade de estudar tal temática justifica-se em função de 
dois aspectos: a intensa ocorrência da erosão nas margens dos rios e as mudanças significativas na configuração e morfologia dos canais amazônicos.

A área de estudos localiza-se em uma zona de perturbação geológica atingida por movimentações neotectônicas, onde segundo Tricart (1977) ocorreu uma auto-captura fluvial pelo rio Solimões, aspecto que ficou evidente em face às interpretações das imagens descritas em folhas planimétricas de 1:250.000, elaboradas a partir de mosaicos semi-controlados de imagem de radar pela Divisão de Cartografia do Projeto RADAMBRASIL (1977).

As "Terras Caídas" constituem uma modalidade erosiva deflagrada por causas naturais, devido ao processo de transporte de sedimentos, deposição e erosão, que ocorrem na fase atual de colmatagem e, configuração da planície fluvial amazônica. A propósito do tema, Carvalho (2006) explica que "terras caídas" corresponde à terminologia regional amazônica utilizada para designar indiferentemente, escorregamento, deslizamento, desmoronamento e desabamentos, movimentos de massa comuns nas margens dos rios de águas brancas. Segundo o autor, o pacote sedimentar deslocado das margens varia em tamanho, atingindo grandes extensões em quilômetros de terras, ou às vezes, dimensões quase impercebíveis de dezenas de metros. Nas margens do rio Solimões-Amazonas e seus grandes afluentes esse processo é intenso em função da configuração de um complexo sistema flúviolacustre.

Para Freitas (2009), a modalidade erosiva do tipo "Terra Caída" é desencadeada por uma combinação de diferentes fatores, onde se destaca em grau de importância, os climáticos, em face aos altos níveis pluviométricos desta região, estimados na ordem de $2.600 \mathrm{~mm} /$ ano. Outros aspectos, como a fragilidade do material das margens e a própria dinâmica que a água do rio, exerce sobre esse material merecem ser destacados.

A literatura sobre a dinâmica natural da modalidade erosiva do tipo "terras caídas", não apresenta um vasto número de trabalhos, devido à complexidade hidrográfica dos ambientes fluviais amazônicos e a intensidade dos processos de morfodinâmica atual, presente nos canais dessa região. Para auxiliar o entendimento de tais questões, a aplicação do SIG demonstrou que é uma ferramenta eficaz, para o entendimento dos processos erosivos, não apenas do 
ponto de vista dos fatores controladores, mas, pelas conseqüências que essa dinâmica acarreta ao ambiente.

\section{2 ÁREA DE ESTUDO}

A área de estudo desta pesquisa correspondeu ao trecho que vai da

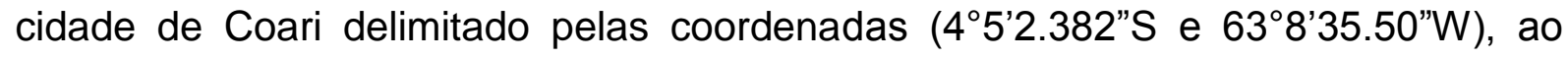
Terminal Hidroviário (356'26.016"S e 639'57.53”W). Esta área possui diferentes ambientes tendo como principal curso d'água o rio Solimões (FIGURA 1). O município de Coari pertence à mesorregião do Centro Amazonense, juntamente com cinco municípios denominados Anamã, Anori, Beruri, Caapiranga e Codajás constituindo uma área territorial de 57.922 km². Pertence à SUB-BACIA 13 (Área de drenagem do rio Amazonas), situada entre o lago Coari e a confluência do rio Purus. 


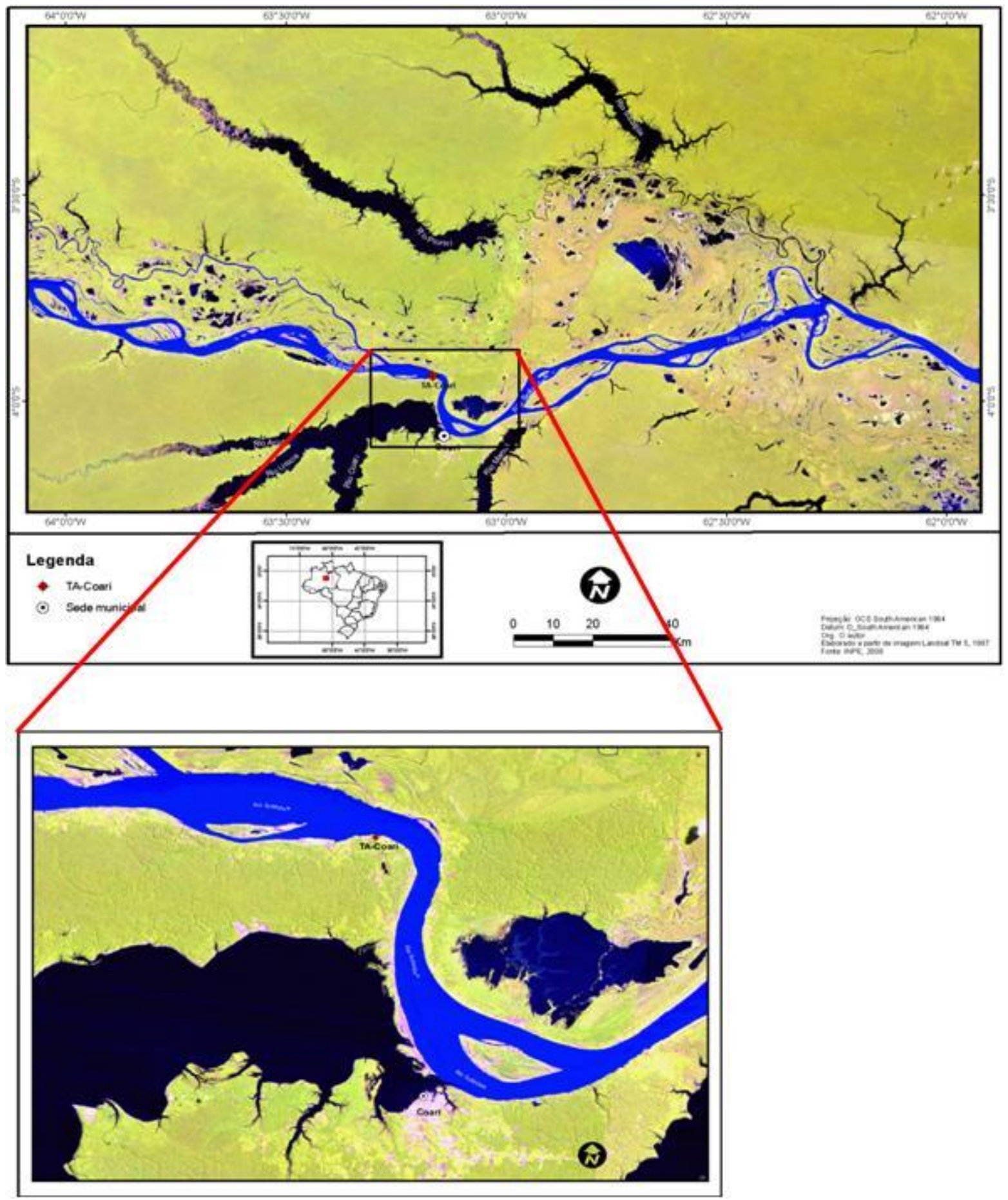

FIGURA 1 - LOCALIZAÇÃO DA ÁREA DE ESTUDO NO MÉDIO SOLIMÕES COARI (AM), IMAGEM DE SATÉLITE LANDSAT TM5 BANDAS 3,4 E 5.

FONTE: INPE (2008); Organizado pelo autor (2009) 


\section{METODOLOGIA}

A metodologia foi organizada em fases distintas que incluíram levantamentos de campo, análises de laboratório e interpretações no gabinete. Divididas em: I - análises de Geoprocessamento; II - análises físicas; III - análises químicas e IV - análises mineralógicas. Os levantamentos de campo foram realizados visando o reconhecimento local e identificação dos pontos de maior erodibilidade, com o auxílio do GPS. Durante esta fase foram incluídas, também, medições batimétricas por meio do ecobatímetro Fishfinder.

I - Análise de Geoprocessamento

Foram realizadas análises de imagens de satélites e radar. As fotointerpretações foram trabalhadas, utilizando-se o Sistema de Informação Geográfica (SIG), visando o reconhecimento, identificação e localização da área base nos limites da área de estudo. A pesquisa compreendeu a aquisição de dados cartográficos analógicos (folhas SA-20-Y-D; SA-20-Y-C; SB-20-V-A; SB-20-W-B) e digitais obtidas do IBGE/CENSIPAM e CPRM. Os modelos SRTM (Shuttle Radar Topography Mission) foram adquiridos no site CGIAR Consortium for Spatial Information $^{3}$ (CGIAR-CSI) imagem de radar/2004, produto disponibilizado de forma gratuita.

No site do INPE (Instituto de Pesquisas Espaciais) foram disponibilizadas imagens Landsat 5 TM, (cenas 233_063 e 062/ 232_063 e 062) referentes ao ano 1987 e CBERS (cenas 175_104 e 105/ 176_104 e 105) referente ao ano de 2008, bandas 3, 4 e 5, tendo como o mês de referência julho (21/07 a 27/7/08) e na escala de 1:250.000. Na 4⿳亠丷a Divisão de Levantamentos em Manaus (Exército) foi realizado o processamento das imagens e sensoriamento remoto utilizando os software ENVI 4.5 e o ArcGIS 9.2. As etapas para análise dos dados foram feitas a partir de três momentos apresentados como pré-processamento, processamento, integração dos dados e avaliação quantitativa.

- No Pré-processamento para a definição da projeção para as imagens e dados vetoriais foram utilizadas as coordenadas geográficas Projeção: GCS South American 1964, Datum: D South American 1964.

\footnotetext{
${ }^{3}$ Consortium for Spatial Information (CGIAR-CSI) site: (http://sttm.csi.cgiar.org/SELECTION/listImages.asp)
} 
- O Processamento compreendeu o georreferenciamento realizando o mosaico das imagens e, em seguida, o recorte no qual foram utilizadas as molduras de corte definidas previamente do retângulo criado em formato shapefile.

a) Vetores: Para o processamento foi realizada a delimitação geral da área, criando-se um shape polígono referente às coordenadas $\left(4^{\circ} 13^{\prime} 2.072^{\prime \prime S}\right.$ e $63^{\circ}$ 39'48.9"W; 4¹2'46.63"S e 62¹6'17.8”W) que envolveram o realce linear e o realce de contraste nas imagens CBERS e LANDSAT, em virtude 17.8"W) e para a seleção e delimitação especifica referente ao trecho de Coari ao Terminal Solimões (TRANSPETRO/PETROBRAS). Também foi gerado a partir do rio Solimões um Buffer de $5 \mathrm{~km}$ para demonstrar a área foco de estudo

b) Raster: Esta fase envolveu o realce linear e o realce de contraste nas imagens CBERS e LANDSAT, em virtude das diferenças no histograma. A imagem de satélite, adquirida pelo sistema sensor apresentou baixo contraste. Dessa forma, para que as informações nela contidas fossem extraídas por um analista humano, o histograma comprimido foi expandido visando o (re) posicionamento das imagens.

Por conseguinte, foi realizado 0 registro das imagens (georreferenciamento). Antes de apresentar os procedimentos operacionais para executar o georreferenciamento de imagens, é importante fazer a distinção entre os termos (registro e georreferenciamento). De acordo com a NPAIS (2002), quando uma imagem é transformada por um modelo matemático específico, para que cada pixel tenha um correspondente em outra imagem, considera-se o registro das imagens. Sendo assim, foram trabalhadas imagens de sensores diferentes, porém na mesma escala de 1.250.000.

- Na Integração dos dados foram utilizados: o recorte da área. O passo seguinte foi a classificação das imagens de 1987 e 2008. No software ENVI 4.5 foi utilizada a Classificação Supervisionada Maxver. De acordo com a NPAIS (2002) a classificação de Máxima Verossimilhança (Maxver) considera a ponderação das distâncias entre médias dos níveis digitais das classes utilizando parâmetros estatísticos.

Foram geradas duas classes: A Classe 1 representando a água e para Classe 2 não água. A classificação utilizada foi a paralela no ENVI 4.5, seguida por uma pós classificação utilizando a tolerância 5. Após a separação das classes, o próximo passo foi eliminar os pontos pequenos de erros computacionais. 
Normalmente o resultado de uma classificação é uma imagem com ruído, causado por "pixels" isolados ou poucos "pixels" atribuídos a outras classes. Por isso, utilizouse a classificação "pixel a pixel".

Outro fator atribuído foi o emprego do filtro, no qual foi utilizado "Filtro da Moda", que tem o propósito de verificar em determinada janela a classe de maior freqüência, atribuindo ao pixel central da janela essa classe.

Por conseguinte, ao final da fase de edição e da classificação foi realizada a vetorização das classes de interesse, que consistiu na conversão das classes do formato matricial para o vetorial. Ressalta-se que as imagens classificadas foram georreferenciadas e a conversão automática produz vetores com as respectivas coordenadas geográficas obtidas a partir do software ArcGIS 9.2, transformando a base de dados para o formato shapefile (FIGURA 2).

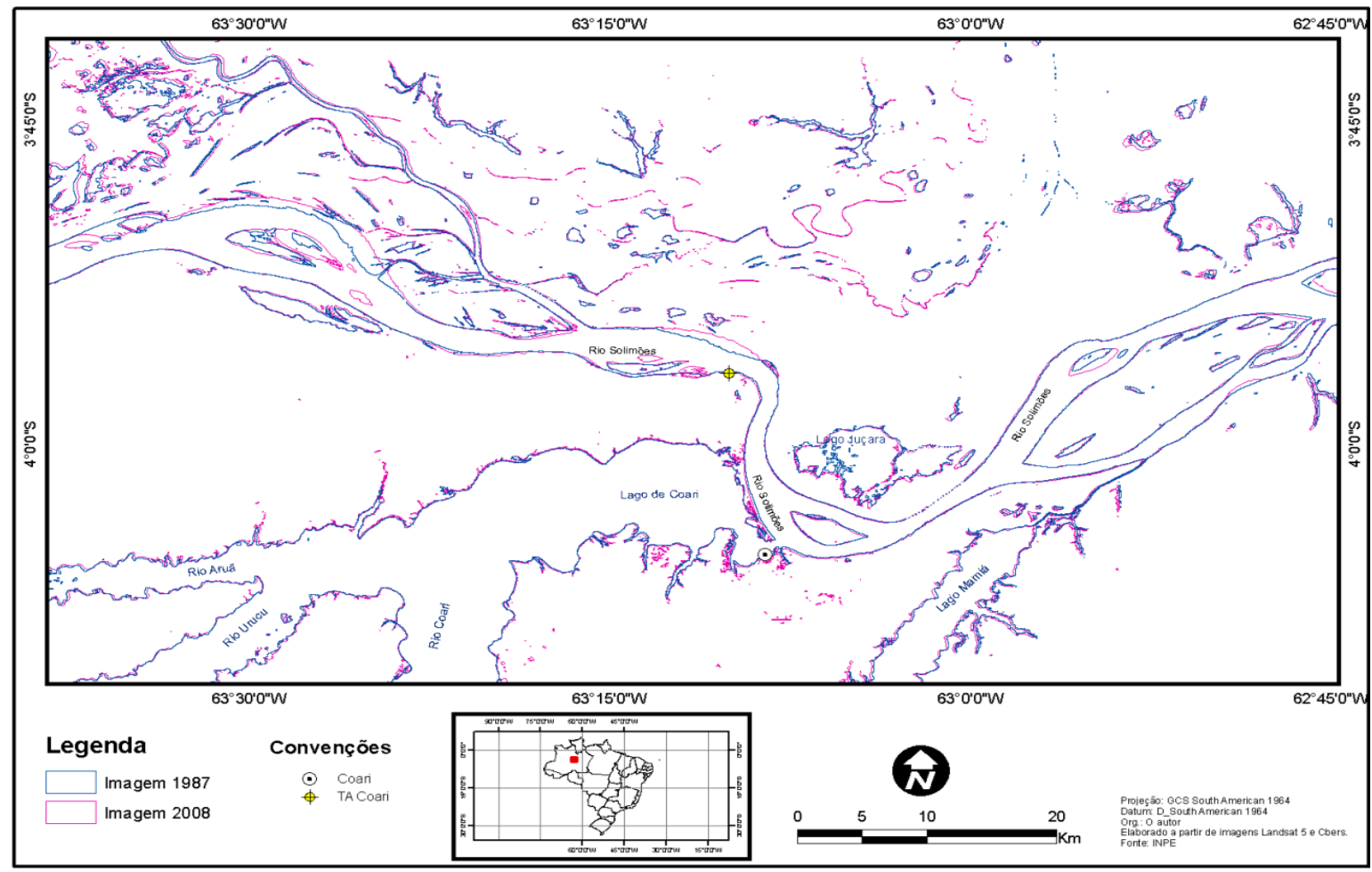

FIGURA 2 - LOCALIZAÇÃO E SOBREPOSIÇÃO DAS IMAGENS, POLÍGONO AZUL DIZ RESPEITO À IMAGEM LANDSAT TM 5 1987, POLÍGONO ROSA REFERENTE A IMAGEM DE SATÉLITE CBERS 2008.

FONTE: Elaborado pelo autor (2009) 
Na Avaliação quantitativa - realizou-se a identificação das áreas como: área 1 margem esquerda $(\mathrm{ME})$, área 1 margem direita $(\mathrm{MD})$, área 2 margem direita (MD), e área 3 margem direita (MD). Em seguida foi feito o cálculo das áreas e identificação dos pontos atingidos por maior aporte erosivo.

II - Análise Física

As coletas de amostra de solo seguiram critérios propostos no Manual de Solos. Para a identificação e reconhecimento das propriedades físicas dos depósitos de várzea, foi realizada a análise granulométrica por via úmida, com a adição de dispersante químico (10 $\mathrm{ml}$ de solução de hexametafosfato) seguindo as normas e procedimentos contidos no Manual da Embrapa (1996). No dia seguinte o conteúdo foi passado em peneira de malha de $0,053 \mathrm{~mm}$, colocada sobre um funil apoiado em suporte, tendo logo abaixo uma proveta de $1000 \mathrm{ml}$. O material retido na peneira foi lavado com jato de água, onde o volume da proveta foi completado.

O passo seguinte foi agitar a suspensão durante 20' com um bastão de furos, marcando-se o tempo. Após concluir a agitação e medir a temperatura da amostra, verificou-se na tabela o tempo de sedimentação da fração argila para $5 \mathrm{~cm}$ de profundidade. Depois de calculado o tempo foi introduzida uma pipeta de $20 \mathrm{ml}$ apoiada em um suporte até a profundidade de $5 \mathrm{~cm}$ e coletada a argila floculada em suspensão. Em seguida, transferiu-se o conteúdo da pipeta para o Becker de $40 \mathrm{ml}$ numerado e colocado na estufa, deixando evaporar completamente a suspensão. Colocado posteriormente em um dessecador foi pesado e se obteve o percentual da fração argila.

Para a identificação da fração areia foi numerado o Becker e pesado. Em seguida, para eliminar o excesso de água foi levado à estufa. Após a secagem foi repesado e assim determinou-se a fração grossa (areia total). A determinação do silte corresponde ao complemento dos percentuais para $100 \%$ obtido por diferença das frações de argila e areia.

\section{III - Análise Química}

Para a análise química foi utilizado o Potenciômetro com eletrodo combinado imerso em suspensão: Líquido água. Foi colocado $10 \mathrm{ml}$ de solo em copo plástico de $100 \mathrm{ml}$ numerado adicionando-se $25 \mathrm{ml}$ água $\left(\mathrm{H}_{2} \mathrm{O}\right)$. Em seguida, agitou-se a amostra com bastão de vidro individual, deixando-a em repouso uma 
hora na proporção de 1: 2,5 onde a leitura foi feita diretamente no aparelho sem cálculos.

IV - Análise Mineralógica

A análise mineralógica feita a partir da Difratometria (Raio-X da fração de argila) realizada em dez amostras, onde parte do feixe incidente que emerge do cristal apresenta o mesmo comprimento de onda, porém em direção diferente (RODRIGUES et al, 2005) para obter-se um resultado qualitativo.

Esse procedimento foi realizado com argilas tratadas para identificar os minerais existentes. A fração de argila foi separada em estado pastoso sobre uma lâmina de vidro com o auxilio de uma espátula. Com outra lâmina o material foi friccionado, o quanto foi necessário para formar uma película fina, secada em temperatura ambiente e levada ao difratômetro.

\section{RESULTADOS E DISCUSSÕES}

\subsection{ANÁLISE GEOPROCESSAMENTO}

A análise multitemporal apontou contornos importantes do canal fluvial no período de 21 anos (1987-2008). Na figura 3, verificou-se a sobreposição das imagens de satélite LANDSAT 1987, os contornos em vermelho em formato shapefile da imagem CBERS 2008. O comportamento estacionário do conjunto de barras e a estabilidade geométrica do canal do Solimões - na área pesquisada são notáveis, se comparadas com o canal do rio Madeira, por exemplo, que apresenta migração de barras e formação de novas ilhas num período inferior a 15 anos (ROZO, 2004). 


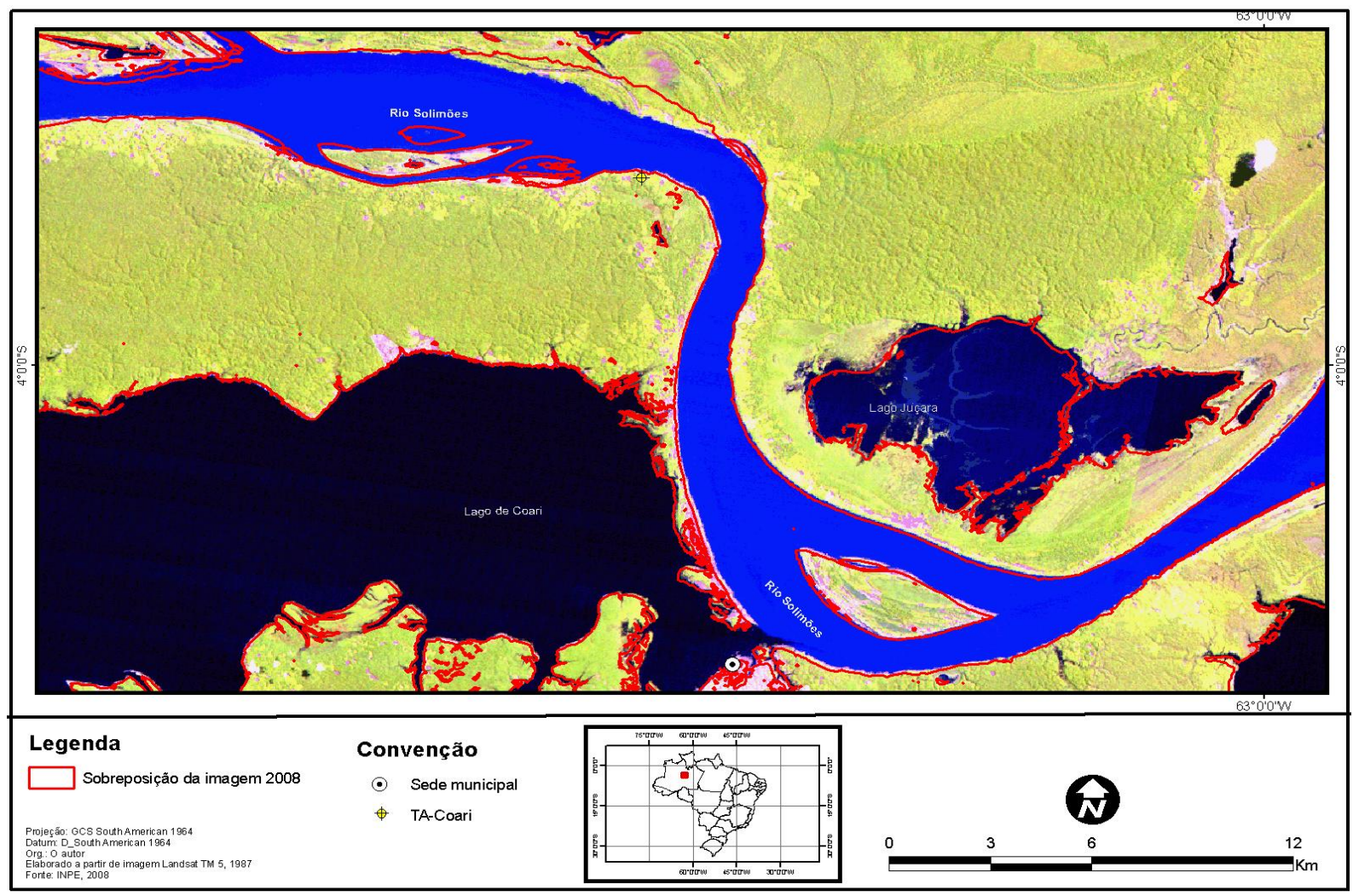

FIGURA 3 - SOBREPOSIÇÃO DE POLÍGONO CBERS 2008 EM IMAGEM LANDSAT TM 51987 (INPE), INDICANDO AS MUDANÇAS NOS CONTORNOS A PARTIR DA EROSÃO DAS MARGENS.

FONTE: Elaborado pelo autor (2009)

A Área 1 (margem esquerda - ME) ilustrada na Figura 4, foi a que visualmente apresentou maiores mudanças na configuração e morfologia das margens. A análise granulométrica dos sedimentos indicou para esta área predominância de composição textural do tipo franco-arenosa (Tabela 2 - Perfil $4 M E)$. Nas demais áreas nos perfis $1 M D, 2 M E, 3 M D, 5 M D$ e $6 M E$ - as evidências foram para textura franco-siltosa.

As interpretações obtidas a partir dos dados de textura indicaram elevados níveis de suscetibilidade à erosão nestas margens, complementando a compreensão desse aspecto, a mensuração do total de áreas em $\mathrm{m}^{2}$ auxiliou a identificação e o reconhecimento das mudanças temporais (TABELA 1). Estes 
aspectos evidenciam a instabilidade das margens na área $1 \mathrm{ME}$ com tendência maior à erosão do que nas demais margens.

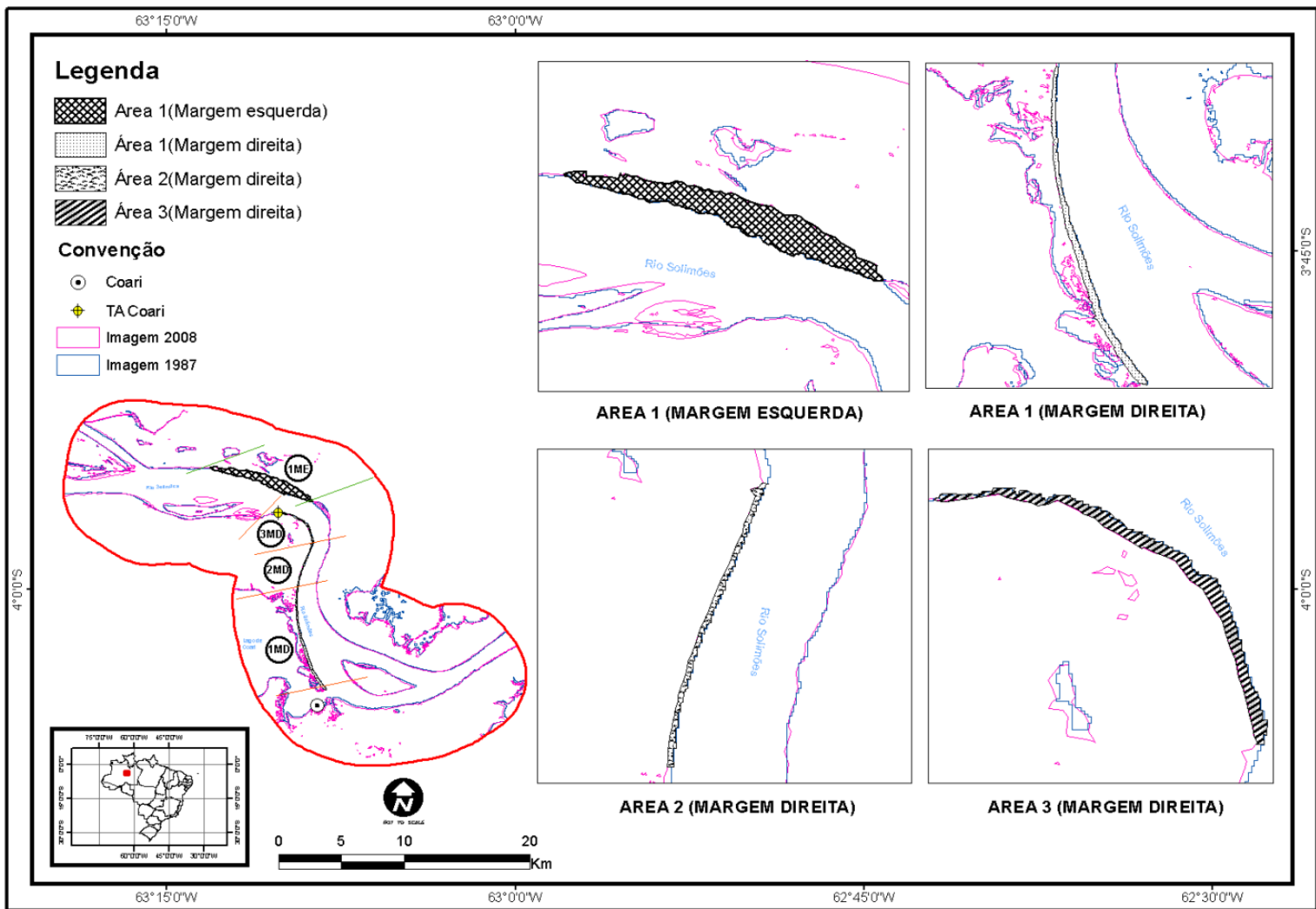

FIGURA 4: IMAGEM DA SOBREPOSIÇÃO DE IMAGENS, ÁREA 1(MARGEM DIREITA) MOSTRA VISIVELMENTE MAIOR ALTERAÇÃO.

FONTE: Elaborado pelo autor (2009) 
TABELA 1 - MUDANÇAS NAS ÁREAS DAS PRINCIPAIS FEIÇÕES DO RIO AMAZONAS, NO TRECHO ENTRE A CIDADE DE COARI E O TERMINAL AQUAVIÁRIO (TA-COARI/TRANSPETRO/PETROBRAS)

\begin{tabular}{|c|c|c|c|}
\hline Local & Rio Solimões & Coordenadas & Área $m^{2}$ \\
\hline $\begin{array}{l}\text { Área } \\
1 \mathrm{ME}\end{array}$ & $\begin{array}{l}\text { Margem esquerda em } \\
\text { frente ao TA-Coari }\end{array}$ & $\begin{array}{l}63^{\circ} 13^{\prime} 7^{\prime \prime} \mathrm{W} / 3^{\circ} 54^{\prime} 37^{\prime \prime} \\
63^{\circ} 8^{\prime} 44^{\prime \prime} / 3^{\circ} 57^{\prime} 27^{\prime \prime S}\end{array}$ & $49.990,523$ \\
\hline $\begin{array}{l}\text { Área } \\
1 \mathrm{MD}\end{array}$ & $\begin{array}{lll}\text { Margem } & \text { direita } \\
\text { Comunidade de } & \text { Santa } \\
\text { Rosa } & & \\
\end{array}$ & $\begin{array}{l}63^{\circ} 9^{\prime} 8 " \mathrm{~W} / 3^{\circ} 59^{\prime} 59^{\prime \prime} \text { e } 63^{\circ} 8^{\prime} 31^{\prime \prime} / \\
4^{\circ} 4^{\prime} 19^{\prime \prime} \mathrm{S}\end{array}$ & $12.731,959$ \\
\hline $\begin{array}{l}\text { Área } \\
2 \mathrm{MD}\end{array}$ & $\begin{array}{ll}\text { Margem } & \text { direita } \\
\text { Comunidade de } & \text { Santa } \\
\text { Rosa } & \\
\end{array}$ & $\begin{array}{l}63^{\circ} 8^{\prime} 54^{\prime \prime} \mathrm{W} / 3^{\circ} 58^{\prime} 54^{\prime \prime} \text { e } 63^{\circ} 9^{\prime} 14^{\prime \prime} / \\
3^{\circ} 60^{\prime} 8^{\prime \prime} \mathrm{S}\end{array}$ & 2.56 \\
\hline $\begin{array}{l}\text { Área } \\
3 \mathrm{MD}\end{array}$ & $\begin{array}{lr}\text { Margem } & \text { direita } \\
\text { Comunidade } & \text { Esperança } \\
\text { II } & \end{array}$ & $\begin{array}{l}63^{\circ \circ} 10^{\prime} 62^{\prime \prime} \mathrm{W} / 3^{\circ} 56^{\prime} 9^{\prime \prime} \\
63^{\circ} 8^{\prime} 17^{\prime \prime} / 3^{\circ} 57^{\prime} 47^{\prime \prime} \mathrm{S}\end{array}$ & $4.482,077$ \\
\hline
\end{tabular}

Fonte: O autor (2009)

A partir da análise quantitativa foi possível verificar a disparidade entre as áreas no que concerne a perda de material das margens no período de 21 anos. Os percentuais indicados no gráfico 1 apresentam mudanças máximas de $72 \%$ para a margem esquerda denominada - $1 \mathrm{ME}$ e mudanças mínimas de $4 \%$ a área da margem direita aqui denominada por $-2 \mathrm{MD}$.

\section{Mudanças nas áreas das principais feições do Solimões}

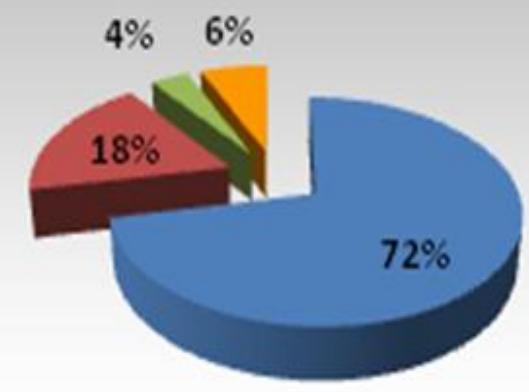

- Área $1 \mathrm{ME}$

Area1MD

Area $2 \mathrm{MD}$

Area 3MD

GRÁFICO 1 - PERCENTUAL DA AMOSTRAGEM FEITA A PARTIR DAS IMAGENS DE SATÉLITE, O DIFERENCIAL DAS MARGENS DURANTE 21 ANOS.

FONTE: O autor (2009) 


\subsection{ANÁLISES FÍSICAS}

$\mathrm{Na}$ interpretação dos resultados granulométricos, dez amostras de solos foram coletadas, sendo que nove indicaram a predominância de textura francosiltosa e somente uma amostra coletada na margem esquerda (perfil $4 \mathrm{ME}$ ) foi identificada como Franco-Arenosa (TABELA 2). Estas condições evidenciam a instabilidade do material sedimentar da várzea, determinada por valores elevados da fração silte expressos entre $347,5 \mathrm{~g} / \mathrm{kg}$ e $739 \mathrm{~g} / \mathrm{kg}$. Dentre as areias, as do tipo fina e muito fina foram indicadas por valores de $30,5 \mathrm{~g} / \mathrm{kg}$ a $539,5 \mathrm{~g} / \mathrm{kg}$. A densidade aparente encontra-se compatível para solos do tipo mineral. Para a densidade real os resultados encontrados estão dentro dos padrões médios e limites de 2,3 e 2,9 $\mathrm{g} / \mathrm{cm}^{3}$. Os resultados de percentuais de porosidade (Volume de Poros Totais (VPT)) variaram entre $41,1 \%$ a $48,2 \%$.

TABELA 2 - DISTRIBUIÇÃO GRANULOMÉTRICA DOS SOLOS ESTUDADOS NA REGIÃO DO MÉDIO SOLIMÕES COARI.

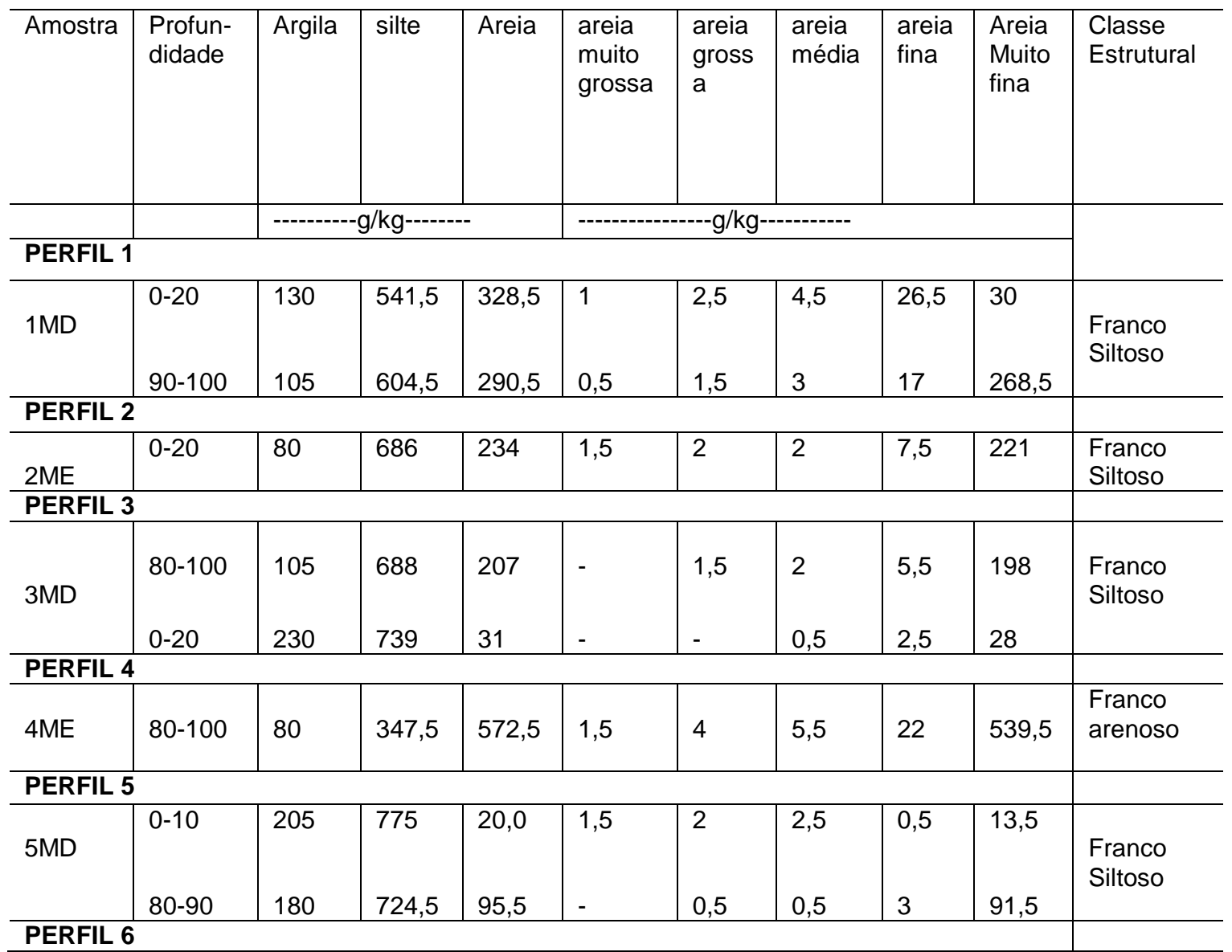




\begin{tabular}{l|l|l|l|l|l|l|l|l|l|l}
\hline 6ME & $0-10$ & 55 & 719,5 & 225,5 & - & 0,1 & 0,1 & 30,5 & 193 & $\begin{array}{l}\text { Franco } \\
\text { Siltoso }\end{array}$ \\
& $80-100$ & 155 & 683,5 & 161,5 & 0,5 & 1,5 & 2,5 & 5,5 & 151,5 & \\
\hline
\end{tabular}

Fonte: O autor (2009)

\subsection{ANÁLISES QUÍMICAS E MINERALÓGICAS}

Para Kielh (1979) o pH dos solos varia, de forma geral, de 4,0 para solos fortemente ácidos e 6,0 a 7,0 de acidez média. Normalmente, a amplitude média de variação do $\mathrm{pH}$ dos solos é de 4,5 a 8,5 . Os valores de $\mathrm{pH}$ variaram de 4.8 a 7.3 pertinentes para os encontrados em áreas flúvio-lacustres, resultantes da planície de inundação.

A análise de difração (Raio $\mathrm{x}$ ) das argilas indicou nas amostras coletadas a presença de Montemorilonita (Mt) mineral (2:1) típica de solos de várzea, a llita (I), a caulinita (K), e a muscovita (M) e outros minerais restritos aos sedimentos derivados das formações geológicas daquela região. Para Kiehl (1979), o grupo de mineral 2:1 apresenta elevada capacidade para a retenção de água, expandindo-se, consideravelmente, quando molhada; a degradação da estrutura da Mt pode dar origem à caulinita $(K)$ mineral 1:1, também encontrada nas amostras e que pode transformar-se em ilita (I), mineral não expansivo quando não recebe por inclusão, iôns de potássio, em suas camadas, outro elemento encontrado nas amostras.

De modo geral, na Amazônia, as características mineralógicas e químicas dos solos são, em grande parte, derivadas pela natureza do material de origem, no que concerne a litologia dessa região.

É importante destacar neste trabalho, que este estudo foi desenvolvido em uma região de planície aluvial. A planície aluvial é considerada como a unidade geomorfológica que margeia rios de "águas brancas" (águas barrentas), ricas em material de suspensão, como é o caso do Amazonas e outros tributários como Juruá, Madeira e Purus, sujeitos à inundação sazonal — denominada regionalmente como várzea.

A várzea corresponde às grandes faixas de terras, podendo alcançar, às vezes, até $100 \mathrm{~km}$ de largura (IRIONDO, 1982), constituindo um complexo sistema de canais, lagos, ilhas e diques marginais. A gênese desse tipo de planície está 
relacionada a processos hidromórficos do Solimões, onde predominam os solos dos tipos Gleissolos e Neossolos Flúvicos.

No caso dos Gleissolos são solos minerais hidromórficos, que apresentam forte gleização resultante de processamento de intensa redução de compostos de ferro, em presença de matéria orgânica, com ou sem alternância de oxidação por efeito de flutuação de nível do lençol freático, em condições de regime de excesso de umidade permanente ou periódico. Estes solos são compostos de argilas e, elevadas taxas de silte, o que contribui em parte, para seu fraco desenvolvimento estrutural, apesar de um elevado teor de material orgânico.

Outro ponto importante a ser mencionado são os aspectos morfológicos dessa planície de inundação, onde a mesma é controlada por arcos estruturais que influenciam na largura, na sinuosidade e no gradiente dos rios (FILIZIOLA et al, 2002 comentando STERNBERG, 1955; TRICART, 1977; DUNNE et al, 1998).

De acordo com Tricart (1977) muitos dos rios na Amazônia têm seus canais ocupados por diques marginais e formas de acumulação cuja localização é influenciada pela tectônica de blocos plioquaternários. Para este autor, "a sedimentação durante a transgressão flandriana foi suficientemente alimentada para colmatar o entalhamento anterior e construir, no seu lugar, uma planície aluvial com grandes sistemas de diques marginais e depressões de pequenas dimensões". Nesta unidade, segundo o autor, os sedimentos, são constituídos por conglomerados granulométricos (areia, silte e argila) do tipo aluviões (antigas e recentes) que estão presentes em todos os rios da região, compondo a maior expressão fisiográfica da bacia Amazônica, que é a planície de inundação do rio Amazonas.

Em se tratando dessa área de estudos, fatores relacionados à neotectonica são bastante representativos para a instalação de processos erosivos e para a dinâmica fluvial. Referente aos resultados alcançados para essa região o rio Solimões, destaca-se por se encontrar predominantemente encaixado na margem direita, formando margem escarpada na formação pertencente ao Neógeno, onde Tricart (1977) relata: "Tal disposição resulta provavelmente de basculamento para o sul, do bloco que domina a depressão de ângulo de falha na qual o rio se alojou".

A autocaptura do rio Solimões (FIGURA 5), nas imediações da cidade de Coari, forma uma curvatura de $90^{\circ}$ prosseguindo em direção preferencial N-S. Este 
aspecto da geomorfologia local constitui uma espécie de anomalia apontada pelo autor como sendo a manifestação mais evidente do basculamento de bloco para sul. Tricart (op.cit) considera ainda que "Toda a tectônica de blocos, com a formação da depressão de ângulo de falha, na qual se alojou o Solimões é posterior ao Quaternário médio" (TRICART, p. 06-07, 1977).

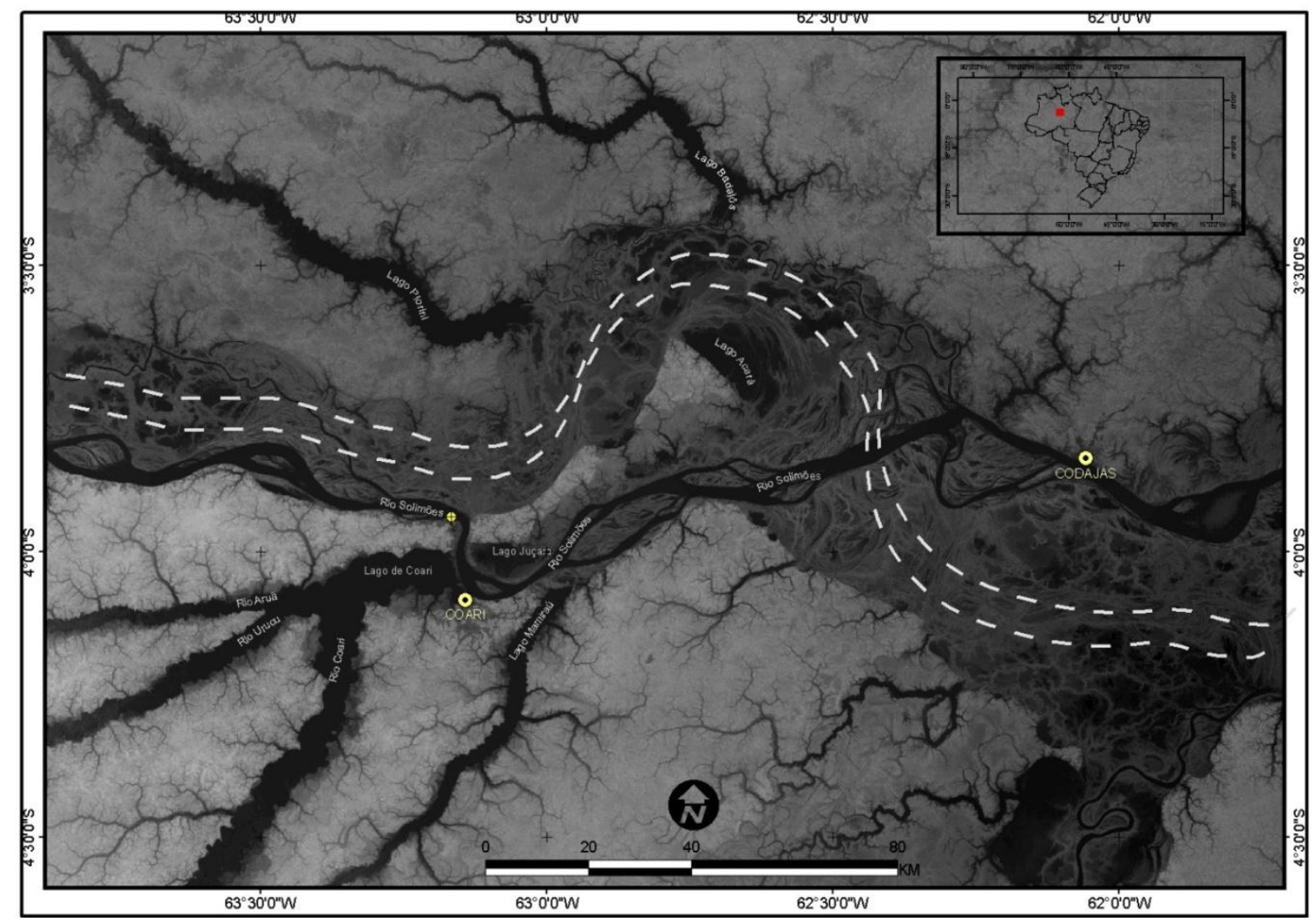

FIGURA 5 - IMAGEM DO MODELO SRTM, MOSTRANDO PALEOGRAFIA DO RIO SOLIMÕES QUE ACARRETOU NA SUA AUTOCAPITURA.

FONTE: Adaptado de SILVA \& ROSSETTI (2009); Organizado pelo autor (2009)

A montante desse estreitamento 0 antigo curso do rio Solimões, se desenvolvia onde hoje se encontram os rios Piorini e Badajós. Havia um antigo percurso do rio Solimões, um paleocanal por $40 \mathrm{~km}$ ao sul da atual posição (RIBEIRO, 2009). Tal mecanismo não seria possível sem uma intervenção tectônica.

De acordo com Ribeiro (2009) a mudança e abandono do antigo leito ocorreram mediante a atuação da Falha Coari/Codajás (ENE-WSW), que funcionou 
provavelmente, como uma falha transcorrente, que deslocou falhas normais que condicionavam a planície e controlavam a drenagem do rio Solimões. Tal disposição resultou, provavelmente, de um basculamento para Sul do bloco que domina a depressão do ângulo de falhas onde o rio se encaixou. Durante o processo de migração, o Solimões teve sua foz afogada próximo à região de Coari, passando a correr ao longo da zona de falha até Codajás, seccionando depósitos aluvionares, e, consequentemente, vem contribuir em conjunto com fatores climáticos, pedológicos dentre outros comentado para a morfordinâmica de canal e das margens.

Com relação ao tipo do material das margens Guerra et al (1999) ressalta que quanto maior o valor de silte mais elevada à suscetibilidade dos solos em seres erodidos. Esta constituição física define um material tipicamente friável, mediante a ação erosiva da água superficial e subsuperficial favorecendo a erosão lateral e o solapamento das margens dos rios, pela ação dos chamados banzeiros - espécies de marolas - que se formam nos rios da bacia amazônica. Os dados obtidos são compatíveis aos estudos realizados por Lima (2001). Este autor menciona que na várzea do Solimões/Amazonas, os solos normalmente apresentam teores elevados de silte e de areia fina, e são, freqüentemente, eutróficos, pois apresentam elevados valores de capacidade de troca de cátions e de cátions trocáveis, especialmente $\mathrm{Ca} 2+, \mathrm{Mg} 2+\mathrm{e}$, em alguns casos, $\mathrm{Na}+$ e $\mathrm{Al} 3+$. Com relação aos minerais, existe dentro de cada textura do solo - no caso as argilas identificadas a partir do Raio $\mathrm{X}$ - minerais bilaminares do grupo da caulinita, que apresentam menor capacidade de absorver íns e água, ao passo que os trilaminares do grupo das montmorilonitas, cujas camadas são mais facilmente separáveis, apresentam capacidade de absorver maior volume de íons e água Krauskopf (1972). Conseqüentemente, a montmorilonita é muito mais expansiva do que a caulinita. Esses dados corroboram com as interpretações de que o tipo de argila encontrada, ou seja, a montmorilonita, ao se expandir na presença de água, possibilita a retenção de água no perfil propiciando processos erosivos como desmoronamento das margens. 


\section{CONCLUSÃO}

A utilização e uso de diferentes sensores orbitais neste caso (imagens de Radar modelo SRTM e satélite Landsat TM 5 e Cbers) possibilitou a verificação das mudanças ocorridas no período de 21 anos e apresentou resultados satisfatórios de identificação das mudanças ocorridas na configuração geomorfológica das margens.

$\mathrm{Na}$ interpretação dos resultados granulométricos foi definido material tipicamente friável (franco-siltoso e franco-arenoso). As propriedades físico-químicas do material tendem a reduzir a resistência dos materiais das margens, e, assim promover a instabilidade e/ou "movimento de terra" pelo processo de enfraquecimento e queda. A ação erosiva da água superficial e subsuperficial favoreceu a erosão lateral e o solapamento que muitas vezes é acentuado pela ação dos banzeiros produzidos por embarcações.

O estudo realizado no trecho da Cidade de Coari ao Terminal Solimões (TA-Coari) mostrou que nessa região a velocidade do processo erosivo das margens, se estende ao longo do curso do rio, deflagrando grande magnitude de erosão lateral.

A análise acerca dos fatores controladores foi de total importância para o entendimento da dinâmica relacionada aos fenômenos das "terras caídas", estando esta pesquisa em concordância com Carvalho (2006), entendendo que se devem rever os fundamentos de erosão fluvial, principalmente, falando do rio Amazonas.

Outro fator importante é o papel da neotectônica associada às zonas de falhas, responsáveis pelas diferentes tipologias de drenagem e geometria dos canais e ao ciclo hidrológico. Com base nestes aspectos observou-se que a erosão é maior quando o rio está enchendo, fator atribuído ao aumento da pressão hidráulica associado às intensas chuvas sobre os materiais das margens (silte, areia e argila). A água sendo o principal agente da dinâmica de um sistema hidrográfico exerce ação mecânica e também química. Dessa maneira, quando se precipita ou escoa dentro do canal, exerce papéis tanto de agente mecânico, como de agente químico.

Com base no exposto, pode-se compreender que a erosão das margens raramente resulta de um único processo, mas sim de uma combinação de fatores como: geológicos, neotectônico, estruturais, climáticos, geomorfológico, pedógicos e, em menor proporção, a ação antrópica. Os conceitos de erosão fluvial contidos na 
literatura são limitados e não permitem a compreensão e explicação da erosão acelerada nas margens do rio Amazonas, uma vez que, grande parte dos estudos de Geomorfologia Fluvial e de Hidrologia se reporta aos ambientes onde os rios são de média e alta declividade, conseqüentemente, com pequena área de transbordamento, o que não pode ser comparado à complexidade do sistema hidrográficos Solimões/Amazonas.

\section{REFERÊNCIAS}

CARVALHO, J. A. L. de. Terras Caídas e Conseqüências Sociais. Paraná da Trindade, município de Itacoatira-Am. (Dissertação). Universidade Federal do Amazonas, Manaus, 2006.

EMBRAPA. Manual para Descrição e Coleta de Solos no Campo. Centro de Pesquisa de Solos. 3ª Edição. Campinas. São Paulo, 1996.

FILIZIOLA, N., GUYOT, J. L., MOLINIER, M., GUIMARÃES, V., OLIVEIRA, E., FREITAS, M. A. II Caracterização Hidrológica da Bacia Amazônica. In: RIVAS, A. e FREITAS, C. (ORG). Amazônia: Uma perspectiva Interdisciplinar. Manaus. EDUA, 2002.

FREITAS, F. T. de. Análise Multitemporal da modalidade erosiva do tipo terra caída na região do Médio Solimões Coari (AM). (Dissertação). Universidade Federal do Amazonas, Manaus, 2009.

GUERRA, A.J.; SILVA, A.S. da; BOTELHO, R.G. Erosão e Conservação dos Solos: Conceitos, Temas e Aplicações Rio de Janeiro: Bertrand Brasil, 1999

IRIONDO, M.H. Geomorfologia da planície amazônica. In: Simpósio do Quartenário do Brasil, 4,. São Paulo, 1982.

KRAUSKOPF, K. B. Introdução à geoquímica. São Paulo: Polígono, 1972. v. 2.

NPAIS. Normas Provisórias para Atualização com Imagem de Satélite. Diretoria de Serviço Geográfico do Exercito. 2002.

KIEHL, E. J. Manual de Edafologia. Relações solo-planta. Ed Agronômica Ceres. São Paulo, 1979.

LIMA, H. N. Gênese, química, mineralógica e micromoforlogia de solos da Amazônia Ocidental. 176p. Tese (Doutorado em solos e Nutrição de Plantas). Universidade Federal de Viçosa, Viçosa. 2001. 
RADAMBRASIL, Projeto. Levantamentos de Recursos Naturais. Departamento Nacional da Produção Mineral. MME/DNPM Folha SA. 20 Manaus. Vol 17 e 18. Rio de Janeiro, 1977 e 1978.

RIBEIRO, O. L. Morfodinâmica do Rio Solimões na Região entre Coari e Anamã, Estado do Amazonas. Manaus. Dissertação de Mestrado, Universidade Federal do Amazonas. Manaus. 2009.

RODRIGUES, C.; ADAMI, S.. Técnicas Fundamentais para Estudos de Bacias Hidrográficas. In: VENTURI, Luis Antônio Bittar (Org.). Praticando Geografiatécnicas de campo e laboratório. São Paulo: Oficina de Textos, 2005.

ROZO, M. G. Evolução Holocênica do rio Amazonas entre a llha do Careiro e a foz do rio Madeira. (Dissertação de Mestrado, Universidade Federal do Amazonas. 2004.

SILVA, C. L.; ROSSETTI, D. de F. História Geológica dos rio da Amazônia. Ciência e Cultura. São Paulo, 2009. Vol. 61 n`3.

SIOLI, H. Alguns resultados e problemas da limnologia amazônica. Belém, IPEAN, Boletim. Técnico, 24. 1951.

TRICART, J. L. F. Tipos de planícies aluviais e de leitos fluviais na Amazônia brasileira. Rio de Janeiro, 1977.

(Recebido em 14.08.2010. Aceito em 16.05.2011) 